\title{
Role of Bax in resveratrol-induced apoptosis of colorectal carcinoma cells Mojgan Mahyar-Roemer ${ }^{1}$, Hans Köhler² and Klaus Roemer*3
}

Address: ${ }^{1}$ Internal Medicine IV, University of Saarland Medical School, D-66421 Homburg/Saar, Germany, ${ }^{2}$ Internal Medicine IV, University of Saarland Medical School, D-66421 Homburg/Saar, Germany and 3Department of Virology, Institute of Medical Microbiology, University of Saarland Medical School, D-66421 Homburg/Saar, Germany

E-mail: Mojgan Mahyar-Roemer - inmmah@uniklinik-saarland.de; Hans Köhler - inhkoe@uniklinik-saarland.de; Klaus Roemer* - vikroe@uniklinik-saarland.de

*Corresponding author

Published: 17 October 2002

BMC Cancer 2002, 2:27
Received: 25 June 2002

Accepted: 17 October 2002

This article is available from: http://www.biomedcentral.com/I47I-2407/2/27

(C) 2002 Mahyar-Roemer et al; licensee BioMed Central Ltd. This article is published in Open Access: verbatim copying and redistribution of this article are permitted in all media for any purpose, provided this notice is preserved along with the article's original URL.

\begin{abstract}
Background: The natural plant polyphenol resveratrol present in some foods including grapes, wine, and peanuts, has been implicated in the inhibition, delay, and reversion of cellular events associated with heart diseases and tumorigenesis. Recent work has suggested that the cancer chemoprotective effect of the compound is primarily linked to its ability to induce cell division cycle arrest and apoptosis, the latter possibly through the activation of pro-apoptotic proteins such as Bax.

Methods: The expression, subcellular localization, and importance of Bax for resveratrolprovoked apoptosis were assessed in human HCTII6 colon carcinoma cells and derivatives with both bax alleles inactivated.

Results: Low to moderate concentrations of resveratrol induced co-localization of cellular Bax protein with mitochondria, collapse of the mitochondrial membrane potential, activation of caspases 3 and 9, and finally, apoptosis. In the absence of Bax, membrane potential collapse was delayed, and apoptosis was reduced but not absent. Resveratrol inhibited the formation of colonies by both HCTII6 and HCTII 6 bax -/- cells.
\end{abstract}

Conclusion: Resveratrol at physiological doses can induce a Bax-mediated and a Bax-independent mitochondrial apoptosis. Both can limit the ability of the cells to form colonies.

\section{Background}

Cancers claim at least six million lifes per annum worldwide, and the common and frequently therapy-resistant colon cancers are among the most notorious. Accordingly, natural food constituents capable of inhibiting, delaying or reversing events associated with tumor initiation, promotion, and progression have attracted much attention. The pharmacologically active trans form of the polyphe- nolic, antifungal phytoalexin resveratrol (3,5,4'-trihydroxy-trans-stilbene) is produced by more than 70 plant species and is reaching particularly high levels in grapes, peanuts and wine [1]. A large number of publications in recent years has shown that physiological quantities of resveratrol can modulate multiple cellular pathways relevant for tumorigenesis, among them phase II drug metabolizing, cyclooxygenase, nitric oxide, DNA-synthesis, and 
inflammatory response, as well as cell survival, cell death and cell cycle pathways [2]. The consensus of the many in vitro- and a limited number of in vivo-studies seems to be that micromolar quantities of the compound can not only counteract tumor initiation through anti-oxidant activities and the inhibition of enzymatic carcinogen conversion [2-4], or counteract tumor promotion through cyclooxygenase and hydroperoxidase inhibition $[5,6]$, but can affect tumor cell proliferation and survival through the inhibition of cell cycle, stimulation of differentiation, and induction of apoptosis [2-4]. The latter effects may be of particular relevance for the anti-tumorigenic activity of resveratrol [2], not least because the cell cycle/cell death machinery is specifically altered in many tumor cells and the targeting of this machinery by resveratrol opens up the possibility to specifically affect tumor cells and spare normal proliferating tissue. The compound indeed seems to possess some specificity for tumor cells [7].

At the level of individual proliferating cells, resveratrol appears to act primarily though the inhibition of the cell cycle [8-14]. Although apoptosis may be provoked in normal, non-transformed proliferating cells exposed to high resveratrol concentrations [11], a temporary, reversible cell cycle arrest in G1 and G2 phase has been reported to result at low to moderate concentrations from activation of the p53 tumor suppressor and, subsequently, from the activation of the p21Cip1 inhibitor of cyclin-dependent kinases $[14,15]$. In tumor cells however, p53 function is frequently lost, and consequently, cells usually arrest in S-phase instead of G1 or G2, probably due to the inhibition of DNA synthesis by resveratrol $[16,17]$. Although this cell cycle arrest is also reversible, cells with altered cell cycle checkpoints can be more prone to apoptotic death $[14,15,18]$.

The precise mechanisms through which resveratrol induces apoptosis are unknown. Together, the available data point to the existence of several apoptotic pathways that can be triggered by the compound, and to the existence of survival pathways that can be inhibited by it. For example, resveratrol has been documented to be able to induce apoptosis through the activation of p53 [19], but also through other mechanisms in wild-type p53-deficient tumor cells [8]. Furthermore, the compound has been shown to inhibit the activation of NFkB transcription factor which serves as a survival factor in some cell types $[20,21]$.

Apoptosis following resveratrol treatment has been reported to be mediated, in dependence on cell type, through the death receptor [22] and mitochondrial pathways $[14,23]$. Recent findings make the involvement of the death receptor pathway questionable though $[24,25]$. For instance, dominant-negative inhibition of this path- way failed to block apoptosis induction by a resveratrol analog [24]. The pro-apoptotic Bax protein is one of the major players in the mitochondrion form of apoptosis [26], and mitochondria-mediated cell death induced by resveratrol may involve stimulation of the expression of the bax gene by $\mathrm{p} 53$ or other transcription factors $[10,14,27,28]$. However, mitochondria-mediated cell death may also involve down-modulation of Bax-antagonists such as $\mathrm{Bcl}-\mathrm{X}_{\mathrm{L}}$ or $\mathrm{Bcl}-2$ [29], or the translocation of Bax from the cytosol to mitochondria ([30] and discussion therein). Since Bax was activated moderately or weakly under resveratrol in some cell types $[10,14,27]$, or was activated only at high drug concentrations although apoptosis was observed at low concentrations as well [14], the present work was designed to address the role of Bax in colon tumor cell apoptosis more directly by studying the effect of the drug on the human HCT116 colon carcinoma cell line and a derivative in which both bax alleles were disrupted by spontaneous frameshift mutation and targeted homologous recombination [31].

\section{Methods}

\section{Reagents and cell culture}

Resveratrol was purchased from Alexis (San Diego, CA). JC-1 and MitoTracker Red were obtained from Molecular Probes (Eugene, OR). ADR, 5-FU, and PI were provided by Sigma (St. Louis, MO). Rabbit polyclonal antibodies Bax N-20, Bcl-XL S-18, Bcl-2 N-19, and cytochrome b were from Santa Cruz Biotechnology (Santa Cruz, CA). Rabbit polyclonal caspase 3 antibody and mouse monoclonal caspase 8 and Bax 6A7 antibodies were purchased from Transduction Laboratories/Pharmingen (San Diego, CA). The rabbit polyclonal caspase 9 antibody detecting a 36 $\mathrm{kDa}$ cleavage product of pro-caspase 9 was from BioVision (Mountain View, CA). Peroxidase-conjugated anti-rabbit and anti-mouse secondary antibodies, the $\beta$-actin and FITC-labeled anti-mouse monoclonal antibodies, and a liquid alkaline phosphatase detection kit were from Sigma. Stock solutions of resveratrol and Mitotracker Red were prepared in DMSO; JC-1 was dissolved in methanol; $\mathrm{ADR}, 5-\mathrm{FU}$, and PI stocks were prepared in water. The HCT116 cells and derivatives were cultured as monolayers at $37^{\circ} \mathrm{C}$ in a humidified $7 \% \mathrm{CO}_{2}$ atmosphere in McCoy's 5A medium supplemented with $10 \%$ FCS. HT29 cells were maintained in DMEM plus 10\% FCS.

\section{Immunoblotting and subcellular fractionation}

Cells were seeded in $10 \mathrm{~cm}$ dishes to approx. 50\% confluence at $24 \mathrm{~h}$ before resveratrol treatment. Protein extracts were prepared by lysing the cultures in $150 \mu \mathrm{l}$ of lysis buffer heated to $90^{\circ} \mathrm{C}$ and containing $50 \mathrm{mM}$ Tris- $\mathrm{HCl}(\mathrm{pH}$ $6.8), 100 \mathrm{mM}$ DTT, $2 \%$ SDS, and $20 \%$ glycerol. Samples containing 15 or $30 \mu \mathrm{g}$ of total cellular protein were subjected to SDS-PAGE and transferred to a nitrocellulose membrane (Immobilon-P, Millipore, Bedford, MA). 
Membranes were then incubated overnight with antibodies directed against $\beta$-actin $(1: 5,000)$, Bax or cytochrome $\mathrm{b}$ (1:500), and Bcl-XL, Bcl-2, or one of the caspases (1:200, respectively). For signal detection, the secondary antimouse antibody was used at dilution of 1:5,000, and the secondary anti-rabbit antibody at 1:1,000. For the preparation of subcellular fractions, at least $10^{7}$ cells were scraped off the dishes, washed with PBS, suspended in 0.5 $\mathrm{ml}$ fractionation buffer (20 mM HEPES pH 7.5, $10 \mathrm{mM}$ $\mathrm{KCl}, 1.5 \mathrm{mM} \mathrm{MgCl}_{2}, 1 \mathrm{mM}$ EGTA, $1 \mathrm{mM}$ EDTA, $1 \mathrm{mM}$ DTT, $0.1 \mathrm{mM} \mathrm{PMSF}$, and $10 \mu \mathrm{g} / \mathrm{ml}$ each of leupeptin, aprotinin, and pepstatin A; supplemented with $250 \mathrm{mM}$ sucrose), and homogenized by 10 strokes with a Dounce homogenizer. Nuclei and residual unlysed cells were pelleted at $750 \mathrm{~g}$ for $5 \mathrm{~min}\left(4^{\circ} \mathrm{C}\right)$. The high membrane (HM) fraction containing the mitochondria was harvested by centrifugation at $10,000 \mathrm{~g}$ for $15 \mathrm{~min}\left(4^{\circ} \mathrm{C}\right)$, and the supernatant was collected as the cytoplasmic fraction. The quality of all fractions was routinely tested by Western blotting with antibodies specific for nuclear proteins (anti-PCNA, p53, Rb), cytoplasmic proteins (anti-eIF4A, $\gamma$-tubulin), and mitochondrial proteins (anti-cytochrome oxidase, cytochrome b, c).

\section{Immunofluorescence and membrane potential changes}

To stain mitochondria (MT), cells were incubated with $250 \mathrm{nM}$ Mitotracker Red in pre-warmed full medium for $30 \mathrm{~min}$ at $37^{\circ} \mathrm{C}$ and washed twice with full medium. For immunofluorescence, cells were washed in pre-warmed full medium and fixed for $15 \mathrm{~min}$ at $37^{\circ} \mathrm{C}$ in full medium containing $3.7 \%$ formaldehyde. The cells were then washed with PBS and permeabilized with $0.2 \%$ Triton X100 in PBS for $5 \mathrm{~min}$ at room temperature. After repeated washes with PBS, cells were incubated with the primary anti-Bax antibodies $(1: 100)$ or appropriate controls for 1 h, washed twice with PBS, exposed to the secondary FITClabeled anti-rabbit antibody (1:50), and finally examined with a Leitz fluorescence microscope. For membrane potential $(\Delta \Psi \mathrm{m})$ analysis, $2 \times 10^{5}$ cells were trypsinized, washed in pre-warmed medium, resuspended in McCoy's 5A medium supplemented with $0.2 \%$ FCS and JC-1 at 10 $\mu \mathrm{g} / \mathrm{ml}$, and incubated for $30 \mathrm{~min}$ at $37^{\circ} \mathrm{C}$. The MT membrane potential is reflected by the quotient of red $v$ s. green fluorescence measured by FACscanning; observation wavelengths were $530 \mathrm{~nm}$ for the green fluorescence and $585 \mathrm{~nm}$ for the red fluorescence.

\section{FACS analysis and colony formation assay}

Cells were seeded in 6-well dishes to approx. $20 \%$ confluency $24 \mathrm{~h}$ prior to resveratrol treatment. Asynchronously growing cultures were harvested by trypsinization, combined with the cells floating in the medium, washed with PBS, resuspended in $100 \mu \mathrm{l}$ of $0.9 \% \mathrm{NaCl}$, squeezed through a 23.5 gauge needle into $0.9 \mathrm{ml}$ of methanol and fixed for $30 \mathrm{~min}$ at $-20^{\circ} \mathrm{C}$. Cells were then repeatedly washed with PBS, resuspended in PBS supplemented with RNase A $(25 \mu \mathrm{g} / \mathrm{ml})$ at approx. $10^{6}$ cells $/ \mathrm{ml}$, and stained with PI $(25 \mu \mathrm{g} / \mathrm{ml})$ for at least $1.5 \mathrm{~h}$ at $4^{\circ} \mathrm{C}$ in the dark. DNA fluorescence was measured with a Becton Dickinson FACScan (Bedford, MA); the Cell Quest software (Becton) was employed for data acquisition and analysis. Cells with a less-than-2n DNA content were apoptotic. For colony formation assays, initially $1.5 \times, 3 \times$, and $4.5 \times 10^{3}$ live cells, counted with a CASY cell counter, were seeded in 25 $\mathrm{cm}^{2}$ tissue culture flasks and incubated for approx. 10 days until colonies formed. Since untreated bax -/- cultures were able to produce approx. $5 \times$ more colonies than the parental HCT116 cells, the numbers of seeded live cells were adjusted to produce equal colony numbers for the drug treatment experiments. Colonies were fixed with $0.25 \%$ glutaraldehyde and stained with crystal violet.

\section{Results}

Human colorectal adenocarcinoma HCT116 is a poorly differentiated, growth factor-insensitive cell line deficient for hMLH1, a homologue of the bacterial Mut L protein and crucial component of DNA mismatch repair. The present study has made use primarily of HCT116 and the isogenic cell lines HCT116 p53-/- and HCT116 bax-/- derived from the parental line by targeted disruption of the p53 alleles or - in the case of the bax alleles - by a combination of spontaneous frameshift mutation and targeted disruption [31,32]. HCT116 cells are responsive to a variety of stresses including DNA damage and spindle disruption, in part owing to the integrity of the wild-type p53 tumor suppressor pathway. For this reason, and since deregulated colon epithelial cells are the supposedly primary targets of natural cancer chemopreventive food constituents, this cell line has been frequently employed for the study of the molecular mechanisms of drug action. We have recently reported that the polyphenol resveratrol present in some foods can increase the steady-state levels of pro-apoptotic Bax protein and induce a mitochondriamediated apoptosis in HCT116 cells independently of p53 [14]. However, although Bax overproduction in response to $100 \mu \mathrm{M}$ resveratrol was weak, and at lower drug doses $(<40 \mu \mathrm{M})$, undetectable (Figure $1 \mathrm{~A})$, doses of 10 to $20 \mu \mathrm{M}$ were able to provoke significant apoptotic cell death (typically 9 to $25 \%$ within 48 h vs. $5 \%$ in mocktreated cultures, Figure $1 \mathrm{~B}$ ). We therefore asked what role, if any, Bax might have in the resveratrol-induced apoptosis of HCT116 cells.

Previous work has documented that subtle shifts in the expression levels of Bax-interacting anti-apoptotic members of the Bcl-2 family of proteins can influence cell survival even when Bax levels are unchanged [29]. We failed to detect changes of the steady-state levels of anti-apoptotic $\mathrm{Bcl}-\mathrm{XL}$ in response to resveratrol (Figure 1A), and Bcl-2 was not detectably produced in HCT116 cells, indicating 
A

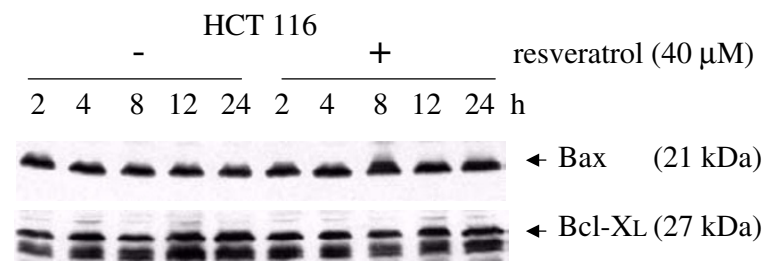

B

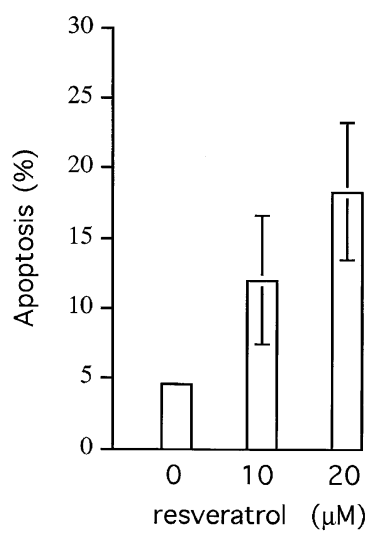

Figure I

Expression of $\mathrm{Bax}$ and $\mathrm{Bcl}-\mathrm{X}_{\mathrm{L}}$, and apoptosis in human HCTII6 colon carcinoma cells treated with low doses of resveratrol. Panel A: Total protein extracts (I5 $\mu \mathrm{g})$ of HCTII6 cultures treated with $40 \mu \mathrm{M}$ resveratrol or only DMSO (the solvent) were prepared at different times and analyzed by immunoblotting, employing the anti-Bax N20 $(I: 500)$ and anti-Bcl- $X_{L}$ antibodies $(I: 200)$. Note that at this low drug concentration, neither the level of Bax nor of $\mathrm{Bcl}-$ $X_{L}$ changed significantly. Panel B: FACS analyses on exponentially growing HCTII6 cultures either mock-treated or treated with low doses of resveratrol for $48 \mathrm{~h}$ exhibited significant apoptosis in the drug-treated cultures. Error bars depict standard deviations of the means of five experiments.

that the apoptotic sensitivity to resveratrol is not regulated via alterations in the Bax/Bcl-XL ratio. Recent work has furthermore shown that Bax levels do not always increase following apoptotic stimuli but that, instead, the occluded N-terminus of Bax may become exposed and the protein may then co-localize with the mitochondria ([30] and discussion therein). When mock-treated formaldehyde-fixed HCT116 cells, p53-deficient HCT116 p53 -/cells, or HCT116 bax -/- cells were stained with anti-Baxantibody 6A7 (Pharmingen/Transduction Labs) or an antibody raised against the conformation-sensitive N-terminus of Bax (N20, amino acids 11 to 30, Santa Cruz), both antibodies recognized a protein in the bax-positive
HCT116 cells and produced a diffuse immunofluorescence signal (see Figure 2, mock-treated cultures), whereas no fluorescence was produced in the bax -/- or isotype controls (not shown), indicating that staining was specific and that the $\mathrm{N}$-terminal epitope of at least a fraction of the Bax molecules was exposed in untreated HCT116 cells after standard fixation.

Treatment of the cells with $100 \mu \mathrm{M}$ resveratrol for $24 \mathrm{~h}$ resulted in the redistribution of Bax, regardless of p53-status, producing a distinctive, punctuate staining pattern in the cytosol with perinuclear concentration, resembling the pattern produced by the mitochondria-specific Mitotracker Red dye (Figure 2A). Confocal imaging confirmed that a fraction of the Bax immunofluorescence merged with the mitochondrial staining; however, a proportion of Bax appeared not to co-localize with the mitochondria (Figure 2B). Furthermore, when cultures were treated with resveratrol and were separated into cell fractions after $24 \mathrm{~h}$, Bax protein accumulated in the high membrane fractions enriched for mitochondria, again regardless of p53-status (Figure 2C). Finally, when we studied the response to $100 \mu \mathrm{M}$ resveratrol of human HT29 colon carcinoma cells expressing the dysfunctional p53273H mutant, HT29 like HCT116 cells showed co-localization of Bax with mitochondria and underwent apoptotic cell death upon drug treatment (data not shown), demonstrating that this effect is not limited to one cell line and is indeed wild-type p53 independent. Together, these results demonstrate that active cellular Bax in colon cancer cells co-localizes with the mitochondria in response to resveratrol exposure, independently of the p53 tumor suppressor.

Active Bax located at the mitochondria can mediate apoptosis [26], and we have recently reported that resveratrol can indeed trigger the mitochondrion form of death in HCT116 cells [14]. Mitochondria-mediated apoptosis is often, though not always, associated with the collapse of the mitochondrial transmembrane potential $\Delta \Psi \mathrm{m}$ as the result of leakiness of the inner mitochondrial membrane [26]. To study whether the translocation of Bax correlates with $\Delta \Psi \mathrm{m}$ changes, exponentially growing cultures of baxpositive and bax-negative cells were treated with $100 \mu \mathrm{M}$ resveratrol or mock-treated for various times and were then incubated with the $\mathrm{J}$ aggregate-forming lipophilic cation JC-1, which as a monomer emits green fluorescence and in a reaction driven by $\Delta \Psi \mathrm{m}$ assembles into a red fluorescence-emitting dimer. In accord with the sensitivity of HCT116 cells to resveratrol-induced apoptosis, and paralleling the co-localization of Bax to the mitochondria, $\Delta \Psi \mathrm{m}$ rapidly dissipated, as indicated by the incremental increase in JC-1 green fluorescence and the lack of a corresponding increase in red fluoresence (Figure 3A). Remarkably, although stable for the first eight hours of drug 
A

HCT116

HCT116 p53-/-

Bax

MT-red

Bax

MT-red
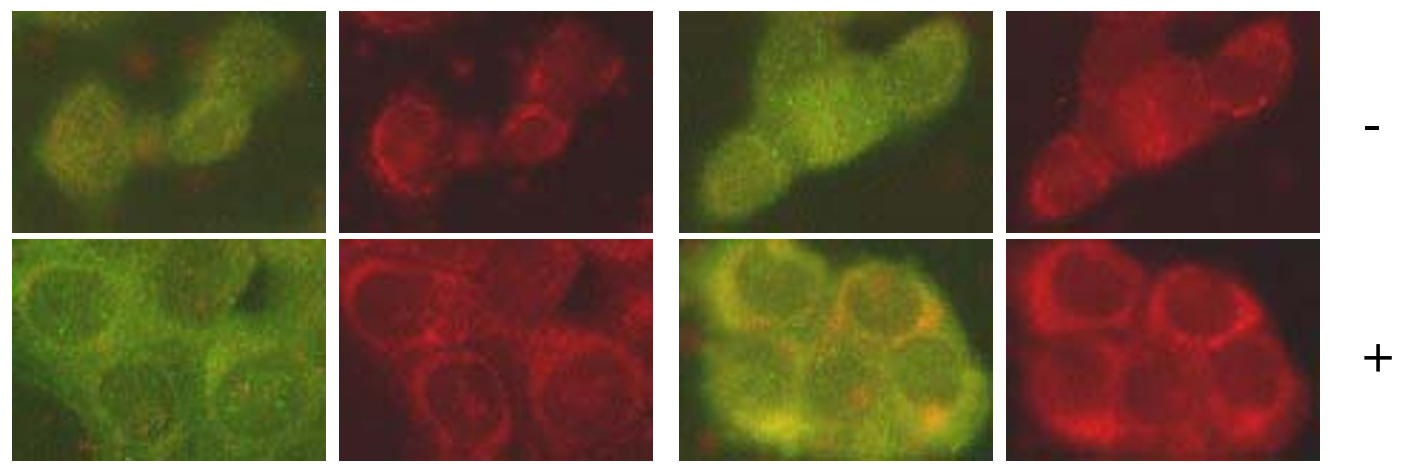

B

HCT116

C HCT116

HCT116

Bax

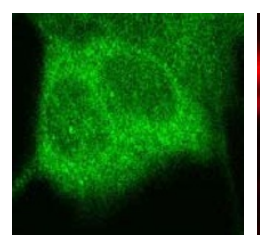

MT-red

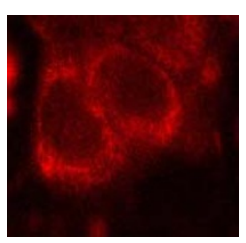

merge

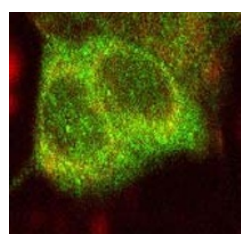

p53-/-

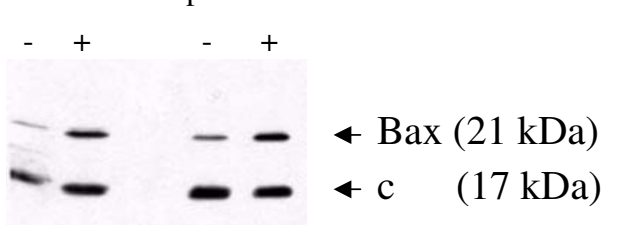

\section{Figure 2}

Subcellular localization of Bax in drug-treated HCTII6 cells and the p53-/- derivatives. Panel A: HCTII6 and HCTII6 p53-/cultures were treated with $100 \mu \mathrm{M}$ resveratrol (+) or mock-treated (-) and, after $24 \mathrm{~h}$, stained with the mitochondria-specific dye Mitotracker Red (MT-red) and anti-Bax N-20 antibody (I:I00). Note the punctuate, cytoplasmic stain with perinuclear concentration produced by the anti-Bax antibody in cells exposed to the drug, resembling the pattern produced by MT-red. Panel B: Confocal microscopy of HCTII 6 cells treated with resveratrol for $24 \mathrm{~h}$ confirmed the co-localization of part of the Bax-produced fluorescence with the MT-red fluorescence. Panel C: Immunoblot analysis on $15 \mu \mathrm{g}$ of total protein from the high membrane (mitochondrial) fraction of cells mock-treated (-) or drug-treated (+) for $24 \mathrm{~h}$. Staining with Bax and cytochrome b (control) antibody (1:500) revealed the increase in Bax levels in the mitochondria fraction of resveratrol-treated cells. The co-localization of Bax with the mitochondria was not dependent on the presence of p53.

treatment, the membrane potential of the bax -/- cells eventually also collapsed, indicating that a Bax-independent, mitochondria-mediated death with delayed kinetics can be triggered in HCT116 cells by resveratrol. To study this further, Western blot analyses with antibodies directed against caspases 3 and 9 were performed. Mitochondria-mediated apoptosis involves the cleavage of procaspase 9 into the $36 \mathrm{kDa}$ active caspase 9, which then cleaves and thereby activates pro-caspase 3 . Resveratrol treatment $(100 \mu \mathrm{M})$ resulted in the increase of active caspase 9 levels, and concomitantly, in the cleavage of procaspase 3, regardless of Bax-status (Figure 3B), supporting the suggestion that resvertrol can provoke both Bax-de- pendent and -independent, mitochondria- and caspasemediated forms of apoptosis in HCT116 cells. As reported before [14], we failed to establish a role of caspase 8 in the resveratrol-provoked cell death, as neither caspase 8 activation in Western blot analyses nor inhibitory effects of the caspase 8 inhibitor IETH-CHO could be observed.

We next asked how the survival of HCT116 and HCT116 bax -/- cultures is affected by resveratrol. When cells were incubated for $48 \mathrm{~h}$ in the presence of increasing concentrations of resveratrol and subsequently FACS-scanned for cell size and DNA content, a dose-dependent induction of apoptosis was observed in both cultures (Figure 4A). In 


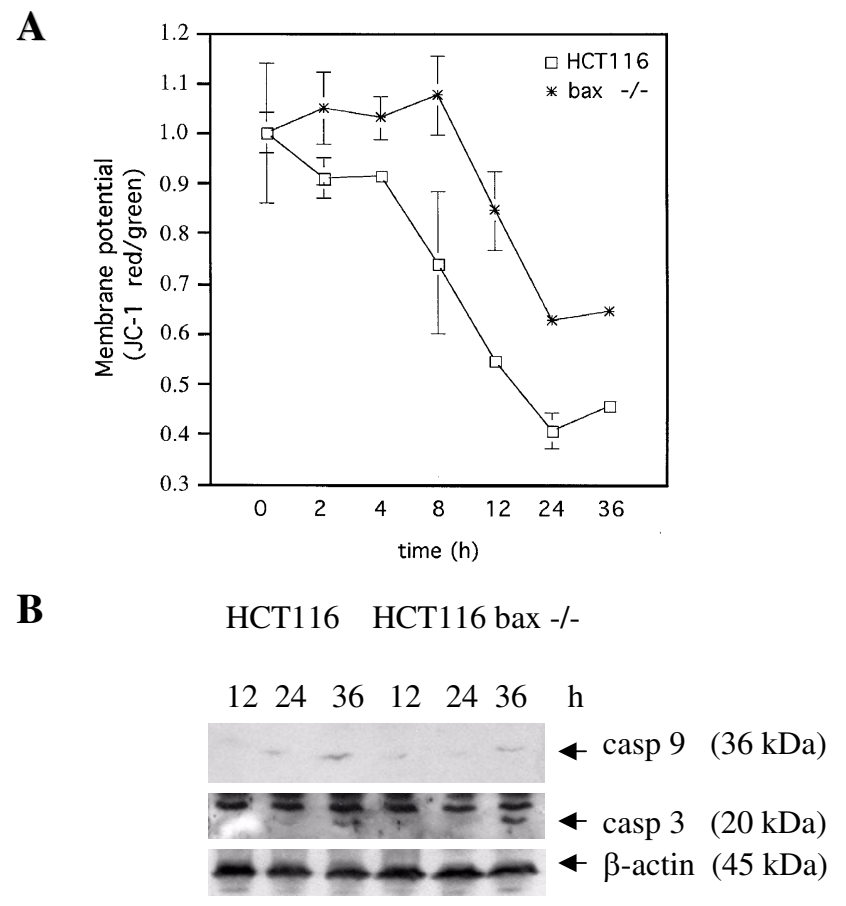

Figure 3

Mitochondrial membrane potential changes and caspase activation. Panel A: Quotient of JC-I red/green fluorescence as an indicator for the membrane potential $\Delta \Psi \mathrm{m}$ in HCTII6 cells and the bax-/- derivatives at different times after exposure to $100 \mu \mathrm{M}$ resveratrol. Note that the absence of Bax delays but fails to completely inhibit membrane potential collapse. Standard deviations were derived from 4 experiments. Panel B: Detection of cleaved (active) caspases (casp) 9 and 3 in total protein extracts from parental and bax-deficient cells exposed to resveratrol. The anti-caspase antibodies were used at a dilution of $\mathrm{I}: 200$. Staining with anti- $\beta$-actin is to show equal protein loading.

HCT116 cultures, the rate of apoptosis increased to approximately $25 \%$ at $20 \mu \mathrm{M}$ resveratrol and plateaued thereafter. Although the bax-deficient cultures showed a similar dose-dependence of apoptosis, the rate of cell death was significantly lower. A time course over $96 \mathrm{~h}$ confirmed that resveratrol at $100 \mu \mathrm{M}$ can provoke apoptosis in both cell lines, but much less efficiently in the bax /- cells (Figure 4B), documenting that resveratrol-induced apoptosis in HCT116 cells is in part, but not entirely, dependent on Bax.

To assess whether the difference in FACS analysis in the apoptosis sensitivity between $b a x+/+$ and bax -/- cells is meaningful, standard colony formation assays were per-
A

B
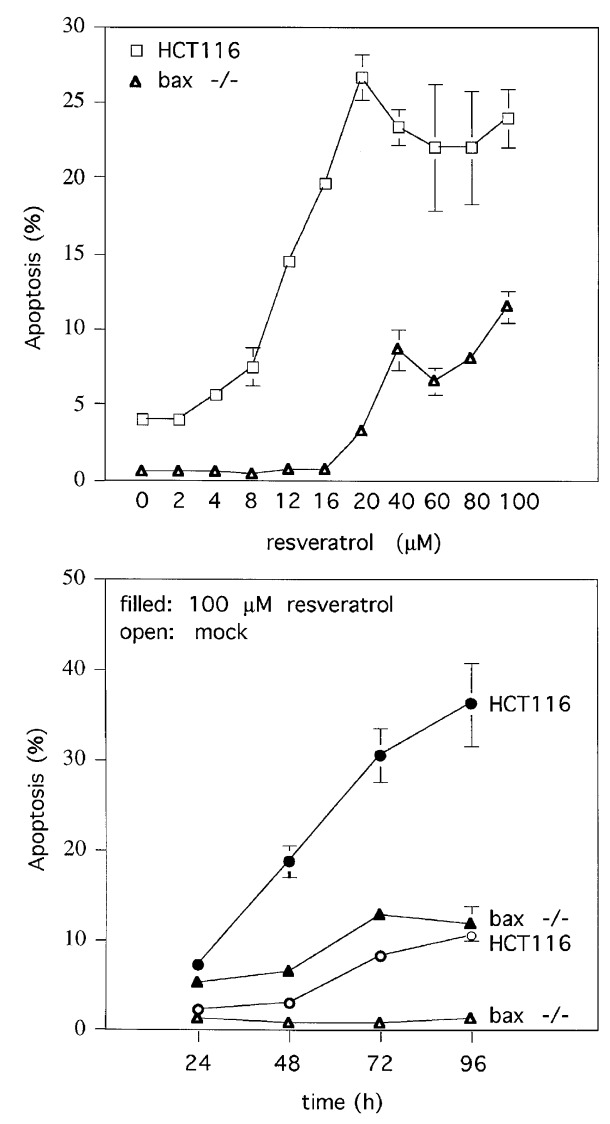

\section{Figure 4}

Effect of resveratrol on the survival of the parental HCTII6 cells and the bax -/- derivatives in culture. Panel A: Treatment of exponentially growing cultures with different doses of resveratrol for $48 \mathrm{~h}$ and quantitation of the numbers of cells with a sub-2n-DNA content by flow-cytometry revealed a dose-dependent increase of apoptosis in both cell lines and a much stronger apoptotic response in the cells expressing Bax, especially at low drug doses. Panel B: Time course of apoptosis in exponentially growing cultures either mocktreated or treated with $100 \mu \mathrm{M}$ resveratrol, documenting the time-dependence of cell death induction. Note the reduced basal level of apoptosis in the bax -/- cultures. Error bars denote standard deviations of the means of four experiments.

formed. In a first set of tests, it was revealed that a short initial exposure of the cultures to $100 \mu \mathrm{M}$ resveratrol for up to $6 \mathrm{~h}$ and removal of the drug thereafter, had no deleterious effect on colony formation (data not shown). This contrasted with the effects of damaging drugs such as adriamycin $(0.34 \mu \mathrm{M})$ or 5 -fluorouracil $(375 \mu \mathrm{M})$, which inhibited colony formation under these conditions, and suggested that resveratrol acts primarily through the reversible inhibition of cellular factors. In the further study, 


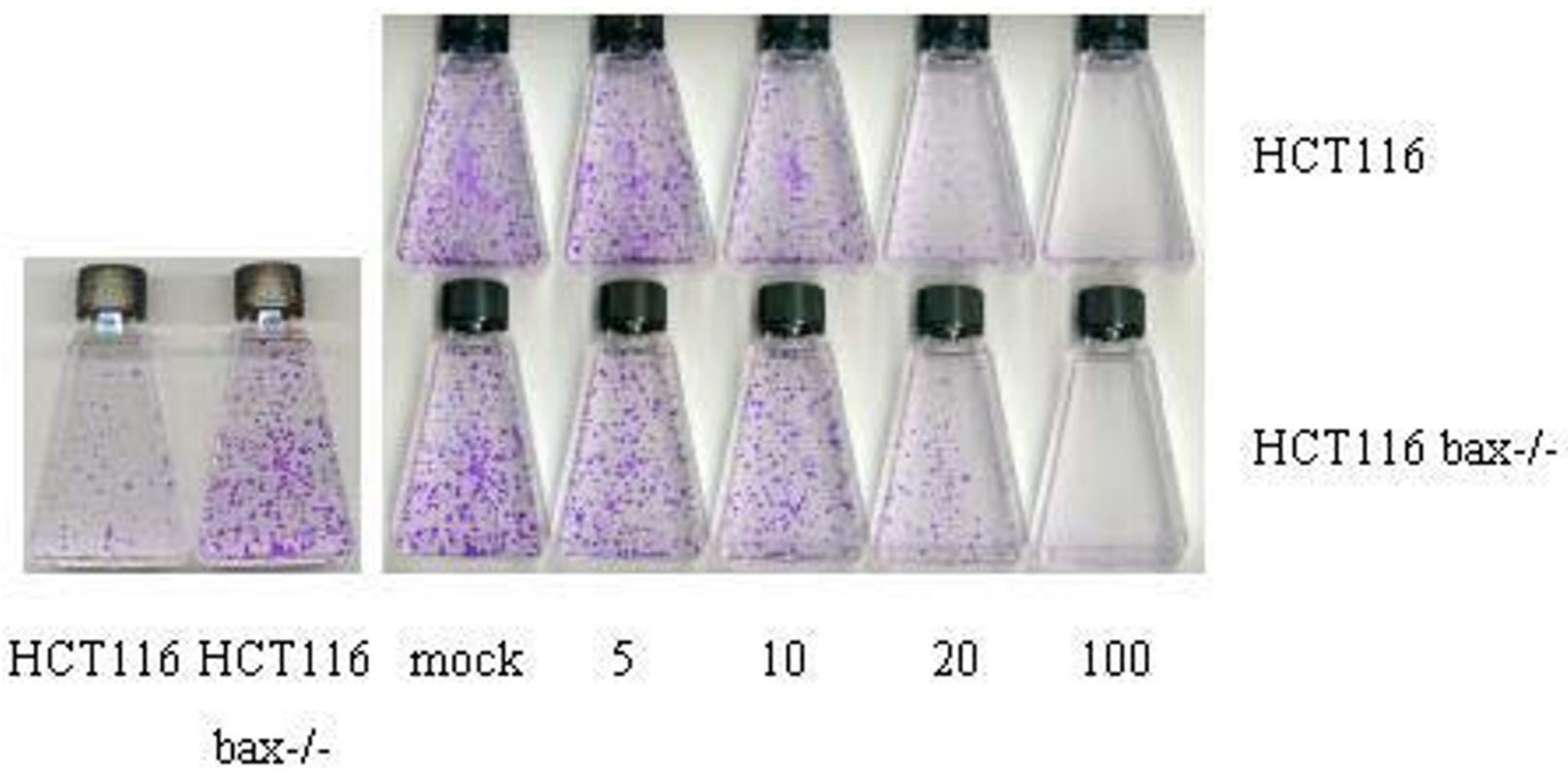

\section{Figure 5}

Representative colony formation assay with HCTII 6 and HCTII 6 bax -/- cells. When $1.5 \times 10^{3}$ live cells, counted in a CASY cell counter, were seeded into $25 \mathrm{~cm}^{2}$ tissue culture flasks and were incubated for 10 days in the absence of drug, bax -/- cells produced more colonies (left figure), indicating the survival advantage per se of bax-deficiency. Right figure: $7.5 \times 10^{3}$ live HCTI I 6 cells and I.5 × $10^{3}$ bax -/- cells were seeded into flasks and exposed to the solvent DMSO (mock) or resveratrol dissolved in DMSO, $24 \mathrm{~h}$ later. Colonies were stained with crystal violet.

cultures were therefore exposed to resveratrol for the duration of the assay. When equal numbers of live $b a x+/+$ and bax -/- cells were seeded and mock-treated, bax -/- cells produced more colonies (Figure 5, left figure), consistent with the much lower basal level of cell death in these cultures (see Figure 4). To be able to compare the effect of resveratrol on colony formation in $b a x+/+$ and -/- cultures, we therefore seeded numbers of live cells that gave rise to similar colony numbers and incubated all cultures for ten days in the presence of different concentrations of resveratrol. The drug decreased the numbers of colonies, and at the highest resveratrol concentration $(100 \mu \mathrm{M})$, no colonies formed, regardless of Bax-status (Figure 5). At lower drug concentration $(20 \mu \mathrm{M})$ however, more colonies formed consistently in the bax -/-cultures when compared with the bax $+/+$ cultures $(62+15$ vs. $24+11$; average + SD from 10 flasks each), and the colonies were generally larger. We interpret this to reflect the lack of inhibition of colony formation by the Bax-dependent form of apoptosis in the bax -/- cultures. In summary, our data thus show that resveratrol at concentrations present in some foods can induce in HCT116 cells i) Bax-dependent, mitochondriamediated apoptosis, regardless of p53-status and involving Bax co-localization with mitochondria, and ii) Bax-independent, mitochondria-mediated death. Both forms of apoptosis may independently limit the ability of the cells to produce colonies.

\section{Discussion}

Resveratrol has been documented to cause apoptosis in a large number of tumor cell lines in vitro $[8,14,19,22,33]$, in a rat model of azoxymethane induced colon carcinogenesis [10], and in a mouse model of familial adenomatous polyposis [34]. The effects of the drug on cell survival are mediated through the activation of downstream effectors such as caspase 3 via two major initiator pathways, the death receptor and the mitochondrial pathway. Although the Fas death receptor pathway has been implicated in some forms of resveratrol-induced apoptosis [22,35], many solid tumors seem to be affected exclusively through the mitochondrial pathway $[14,23]$, which intimately involves the $\mathrm{Bcl}-2$ protein family members of cell survival regulators including the anti-apoptotic $\mathrm{Bcl}-2$ and $\mathrm{Bcl}-\mathrm{X}_{\mathrm{L}^{\prime}}$ and the pro-apoptotic $\mathrm{BH}-123$ protein Bax [26]. Recent work has shown that Bax can be an important mediator of anticancer drug-induced cell death. For example, nonsteroidal anti-inflammatory drugs (NSAIDs) cause Bax-dependent apoptosis in human HCT116 colon carcinoma cells [31]. In this system, the NSAID-provoked cell death was associated with a downregulation of Bax-antag- 
onist Bcl- $\mathrm{X}_{\mathrm{L}}$. In other model systems, Bax was overproduced in response to drugs, including resveratrol $[10,14]$. We have shown in the present paper that a further Bax-dependent mechanism of resveratrol-induced apoptosis may be active - aside from alterations of the Bax:Bcl- $\mathrm{X}_{\mathrm{L}}$ or Bax:Bcl-2 ratios by Bax overproduction or antagonist downregulation: the subcellular redistribution of present Bax protein. Since Bax expression was stimulated only at high resveratrol concentrations while Bax translocation and mitochondria-mediated cell death were observed also at low concentrations, we asked what relevance Bax might have for the chemopreventive activity of the compound.

Our results show that the lack of Bax in HCT116 colon carcinoma cells attenuates but fails to completely inhibit the resveratrol-induced mitochondrial form of apoptosis. This finding is in accord with a recent report showing that stable overexpression of Bax-antagonist Bcl-2 in U937 cells reduces, but does not prevent, resveratrol-provoked death [36]. Along the same line, HCT116 bax -/- cells exhibited a reduced sensitivity to apoptosis induction by the anticancer drug 5-FU, but were not completely resistant like they were in response to the NSAID sulindac [31]. One function of Bax and the related BH-123 protein Bak is the induction of mitochondrial outer membrane permeability, which eventually results in the activation of apoptosis-executing caspases. Cells from mice deficient for both Bax and Bak, but not cells deficient for one or the other only, are almost completely resistant to mitochondria-mediated apoptosis [37], suggesting that these proteins have redundant functions in this pathway. Bak is robustly expressed in HCT116 cells, and recent work has shown that bax-deficient HCT116 cells are more sensitive to apoptosis-provoking drugs such as ceramide than other bax-deficient cells [38]. Whether Bak complements the lack of Bax in HCT116 bax -/- cells treated with resveratrol remains to be seen; however, recent observations with isolated rat mitochondria indicate that the drug is also able to contribute directly to the opening of the mitochondrial permeability transition pore complex and thereby induce the collapse of $\Delta \Psi \mathrm{m}$ without involving the Bax/Bak proteins [23]. Combined, the available data thus indicate that the chemopreventive agent resveratrol can affect the survival of tumor cells through several different pathways.

Most colorectal tumor cell lines apparently show decreases in the ratio of the pro-apoptotic Bax and the anti-apoptotic $\mathrm{Bcl}-\mathrm{X}_{\mathrm{L}}$, and recent observations suggest that mutational inactivation of the bax gene may be frequent in the HNPCC-predisposition to colorectal cancer and may render these cancers resistant to important cancer chemopreventives such as the NSAIDs [31]. The natural plant polyphenol resveratrol, in contrast, can trigger several different mitochondrial apoptosis pathways, and has actually been demonstrated to prevent the formation of colon tumors and reduce the formation of small intestinal tumors by $70 \%$ in a mouse model of familial adenomatous polyposis [34]. One might therefore consider resveratrol or derivatives of it, possibly in combination with other drugs, as a chemopreventive approach to the management of patients with hereditary predispositions to colorectal cancer.

\section{Conclusions}

Low to moderate doses of the natural cancer chemopreventive ingredient of some foods, resveratrol, induce mitochondrial apoptosis but fail to stimulate Bax expression or alter the Bax:Bcl- $\mathrm{X}_{\mathrm{L}}$ ratio in human HCT116 colon carcinoma cells. Instead, the compound induces co-localization of active Bax protein with the mitochondria. HCT116 cells with both bax alleles inactivated undergo mitochondrial apoptosis in response to resveratrol less efficiently than the parental cells, yet cell death through the mitochondrial pathway is not completely inhibited. Thus, resveratrol can activate Bax-dependent and -independent forms of mitochondrial apoptosis. Both forms can independently limit the formation of colonies.

\section{Abbreviations}

ADR: Adriamycin, a potent DNA-damaging anticancer drug; 5-FU: 5-fluorouracil, an anticancer drug affecting DNA and RNA metabolism; MT: mitochondria; $\Delta \Psi \mathrm{m}$ : mitochondrial transmembrane potential, can break down upon transient or permanent permeabilization of inner MT membrane; HNPCC: hereditary non-polyposis colorectal cancer, the commonest form of hereditary predisposition to colorectal cancer.

\section{Competing interests}

None declared.

\section{Authors' contributions}

MM-R conducted the protein expression, subcellular localization and apoptosis studies. HK participated in the design and coordination of the study. KR performed the colony formation assays and drafted the manuscript.

\section{Acknowledgements}

We thank Bert Vogelstein for the HCTII 6 cell lines. This research was supported by a grant from the German Research Foundation (DFG) to K.R.

\section{References}

I. Kopp P: Resveratrol, a phytoestrogen found in red wine. A possible explanation for the conundrum of the 'French paradox'? Eur J Endocrinol 1998, 138:619-620

2. Bhat KP, Kosmeder JMn, Pezzuto JM: Biological effects of resveratrol. Antioxid Redox Signal 2001, 3:104|-1064

3. Jang M, Cai L, Udeani GO, Slowing KV, Thomas CF, Beecher CW, et al: Cancer chemopreventive activity of resveratrol, a natural product derived from grapes. Science 1997, 275:218-220

4. Ciolino HP, Yeh GC: The effects of resveratrol on CYPIAI expression and aryl hydrocarbon receptor function in vitro. Adv Exp Med Biol 200I, 492: 183-193 
5. Mutoh M, Takahashi M, Fukuda K, Matsushima Hibiya Y, Mutoh H, Sugimura T, et al: Suppression of cyclooxygenase-2 promoterdependent transcriptional activity in colon cancer cells by chemopreventive agents with a resorcin-type structure. Carcinogenesis 2000, 21:959-963

6. Subbaramaiah K, Chung WJ, Michaluart P, Telang N, Tanabe T, Inoue $\mathrm{H}$, et al: Resveratrol inhibits cyclooxygenase-2 transcription and activity in phorbol ester-treated human mammary epithelial cells. J Biol Chem 1998, 273:2। 875-2।882

7. Gautam SC, Xu YX, Dumaguin M, Janakiraman N, Chapman RA: Resveratrol selectively inhibits leukemia cells: a prospective agent for ex vivo bone marrow purging. Bone Marrow Transplant 2000, 25:639-645

8. Joe AK, Liu H, Suzui M, Vural ME, Xiao D, Weinstein IB: Resveratrol induces growth inhibition, S-phase arrest, apoptosis, and changes in biomarker expression in several human cancer cell lines. Clinical Cancer Research 2002, 8:893-903

9. Hsieh TC, Juan G, Darzynkiewicz Z, Wu JM: Resveratrol increases nitric oxide synthase, induces accumulation of p53 and p2I(WAFI/CIPI), and suppresses cultured bovine pulmonary artery endothelial cell proliferation by perturbing progression through S and G2. Cancer Res 1999, 59:2596-260I

10. Tessitore L, Davit A, Sarotto I, Caderni G: Resveratrol depresses the growth of colorectal aberrant crypt foci by affecting bax and p2 I (CIP) expression. Carcinogenesis 2000, 21:1619-1622

II. Holian O, Walter RJ: Resveratrol inhibits the proliferation of normal human keratinocytes in vitro. J Cell Biochem 200I, Suppl 36:55-62

12. Ahmad N, Adhami VM, Afaq F, Feyes DK, Mukhtar H: Resveratrol causes WAF-I/p2I-mediated G(I)-phase arrest of cell cycle and induction of apoptosis in human epidermoid carcinoma A43 I cells. Clin Cancer Res 200I, 7:|466-|473

13. Park JW, Choi YJ, Jang MA, Lee YS, Jun DY, Suh SI, et al: Chemopreventive agent resveratrol, a natural product derived from grapes, reversibly inhibits progression through $\mathbf{S}$ and $\mathbf{G 2}$ phases of the cell cycle in $\mathbf{U 9 3 7}$ cells. Cancer Lett 200I, I 63:4349

14. Mahyar Roemer M, Katsen A, Mestres P, Roemer K: Resveratrol induces colon tumor cell apoptosis independently of p53 and precede by epithelial differentiation, mitochondrial proliferation and membrane potential collapse. Int J Cancer 200I, 94:615-622

15. Mahyar Roemer M, Roemer K: p2 I Wafl/Cip I can protect human colon carcinoma cells against p53-dependent and p53independent apoptosis induced by natural chemopreventive and therapeutic agents. Oncogene 200I, 20:3387-3398

16. Fontecave M, Lepoivre M, Elleingand E, Gerez C, Guittet O: Resveratrol, a remarkable inhibitor of ribonucleotide reductase. FEBS Lett 1998, 42 I:277-279

17. Sun NJ, Woo SH, Cassady JM, Snapka RM: DNA polymerase and topoisomerase II inhibitors from Psoralea corylifolia. I Nat Prod 1998, 61:362-366

18. Bunz F, Hwang PM, Torrance C, Waldman T, Zhang Y, Dillehay L, et al: Disruption of p53 in human cancer cells alters the responses to therapeutic agents. J Clin Invest 1999, 104:263-269

19. Huang C, Ma WY, Goranson A, Dong Z: Resveratrol suppresses cell transformation and induces apoptosis through a p53-dependent pathway. Carcinogenesis 1999, 20:237-242

20. Holmes McNary M, Baldwin AS Jr: Chemopreventive properties of trans-resveratrol are associated with inhibition of activation of the IkappaB kinase. Cancer Res 2000, 60:3477-3483

21. Manna SK, Mukhopadhyay A, Aggarwal BB: Resveratrol suppresses TNF-induced activation of nuclear transcription factors NFkappa B, activator protein-I, and apoptosis: potential role of reactive oxygen intermediates and lipid peroxidation. J Immunol 2000, I 64:6509-6519

22. Clement MV, Hirpara JL, Chawdhury SH, Pervaiz S: Chemopreventive agent resveratrol, a natural product derived from grapes, triggers CD95 signaling-dependent apoptosis in human tumor cells. Blood 1998, 92:996-1002

23. Tinhofer I, Bernhard D, Senfter M, Anether G, Loeffler M, Kroemer $G$, et al: Resveratrol, a tumor-suppressive compound from grapes, induces apoptosis via a novel mitochondrial pathway controlled by Bcl-2. FASEB J 2001, I5:1613-1615

24. Wieder T, Prokop A, Bagci B, Essmann F, Bernicke D, Schulze Osthoff $\mathrm{K}$, et al: Piceatannol, a hydroxylated analog of the chemopre- ventive agent resveratrol, is a potent inducer of apoptosis in the lymphoma cell line BJAB and in primary, leukemic lymphoblasts. Leukemia 200I, I 5:1735-1742

25. Bernhard D, Tinhofer I, Tonko M, Hubl H, Ausserlechner MJ, Greil R et al: Resveratrol causes arrest in the S-phase prior to Fas-independent apoptosis in CEM-C7H2 acute leukemia cells. Cell Death Differ 2000, 7:834-842

26. Kroemer G, Reed JC: Mitochondrial control of cell death. Nat Med 2000, 6:1081-1092

27. Lu J, Ho CH, Ghai G, Chen KY: Resveratrol analog, 3,4,5,4'-tetrahydroxystilbene, differentially induces pro-apoptotic p53/ Bax gene expression and inhibits the growth of transformed cells but not their normal counterparts. Carcinogenesis 200I, 22:321-328

28. Lee SH, Ryu SY, Kim HB, Kim MY, Chun YJ: Induction of apoptosis by 3,4'-dimethoxy-5-hydroxystilbene in human promyeloid leukemic HL-60 cells. Planta Med 2002, 68: I23-I 27

29. Vander Heiden MG, Thompson $\mathrm{CB}$ : $\mathbf{B c l - 2}$ proteins: regulators of apoptosis or of mitochondrial homeostasis? Natue Cell Biol I 999, I:E209-216

30. Makin GWJ, Corfe BM, Griffiths GJ, Thistlethwaite A, Hickman JA Dive C: Damage-induced Bax N-terminal change, translocation to mitochondria and formation of Bax dimers/complexes occur regardless of cell fate. EMBO J 200I, 20:6306-63 I 5

31. Zhang L, Yu J, Park BH, Kinzler KW, Vogelstein B: Role of Bax in the apoptotic response to anticancer agents. Science 2000 , 290:989-992

32. Bunz F, Dutriaux A, Lengauer C, Waldman T, Zhou S, Brown JP, et al: Requirement for p53 and p2I to sustain $\mathbf{G 2}$ arrest after DNA damage. Science 1998, 282: |497-I50 I

33. Ragione FD, Cucciolla V, Borriello A, Pietra VD, Racioppi L, Soldati $\mathrm{G}$, et al: Resveratrol arrests the cell division cycle at $\mathbf{S} / \mathbf{G} 2$ phase transition. Biochem Biophys Res Commun I998, 250:53-58

34. Schneider Y, Duranton B, Gosse F, Schleiffer R, Seiler N, Raul F- Resveratrol inhibits intestinal tumorigenesis and modulates host-defense-related gene expression in an animal model of human familial adenomatous polyposis. Nutr Cancer 200I, 39: $102-107$

35. Tsan MF, White JE, Maheshwari JG, Bremner TA, Sacco J: Resveratrol induces Fas signalling-independent apoptosis in THP-I human monocytic leukaemia cells. Br J Haematol 2000, 109:405412

36. Park JW, Choi YJ, Suh SI, Baek WK, Suh MH, jin IN, et al: Bcl-2 overexpression attenuates resveratrol-induced apoptosis in U937 cells by inhibition of caspase-3 activity. Carcinogenesis 200।, 22: I633-1639

37. Lindsten T, Ross AJ, King A, Zong WX, Rathmell JC, Shiels HA, et al: The combined functions of proapoptotic Bcl-2 family members bak and bax are essential for normal develpment of multiple tissues. Mol Cell 2000, 6:1389-1399

38. von Haefen C, Wieder T, Gillissen B, Starck L, Graupner V, Dorken $B$, et al: Ceramide induces mitochondrial activation and apoptosis via a Bax-dependent pathway in human carcinoma cells. Oncogene 2002, 2 I:4009-4019

\section{Pre-publication history}

The pre-publication history for this paper can be accessed here

http://www.biomedcentral.com/1471-2407/2/27/prepub 